\title{
Impact of Shenfu injection on a composite of organ dysfunction development in critically ill patients with coronavirus disease 2019 (COVID-19): A structured summary of a study protocol for a randomized controlled trial
}

Zong-Yu Wang ${ }^{1}$, Shou-Zhi Fu², Liang Xư ${ }^{3}$, Shu-Sheng Li ${ }^{4}$, Ke-Jian Qiann ${ }^{5}$ Xian-Di He ${ }^{6}$, Guo-Chao Zhu', Liang-Hai Li ${ }^{8}$, Jun Zhang ${ }^{9}$, Wen-Fang Li ${ }^{10}$, Bing-Yu Qin ${ }^{11}$, Chen-Liang Zhou ${ }^{12}$ and Peng-Lin Ma ${ }^{1 *}$

\begin{abstract}
Objectives: This study aims to determine the protection provided by Shenfu injection (a traditional Chinese medicine) against development of organ dysfunction in critically ill patients with coronavirus disease 2019 (COVID-19).

Trial design: This study is a multicenter, randomized, controlled, open-label, two-arm ratio 1:1, parallel group clinical trial. Participants: The patients, who are aged from 18 to 75 years old, with a confirmed or suspected diagnosis of severe or critical COVID-19, will be consecutively recruited in the study, according to the guideline on diagnosis and treatment of COVID-19 (the $7^{\text {th }}$ version) issued by National Health Commission of the People's Republic of China.

Exclusion criteria include pregnant and breastfeeding women, atopy or allergies to Shenfu Injection (SFI), severe underlying disease (malignant tumor with multiple metastases, uncontrolled hemopathy, cachexia, severe malnutrition, HIV), active bleeding, obstructive pneumonia caused by lung tumor, severe pulmonary interstitial fibrosis, alveolar proteinosis and allergic alveolitis, continuous use of immunosuppressive drugs in last 6 months, organ transplantation, expected death within 48 hours, the patients considered unsuitable for this study by researchers.

The study is conducted in 11 ICUs of designated hospitals for COVID-19, located in 5 cities of China.
\end{abstract}

Intervention and comparator: The enrolled patients will randomly receive $100 \mathrm{ml} \mathrm{SFI} \mathrm{(study} \mathrm{group)} \mathrm{or} \mathrm{identical} \mathrm{volume}$ of saline (control group) twice a day for seven consecutive days. Patients in the both groups will be given usual care and the necessary supportive therapies as recommended by the latest edition of the management guidelines for COVID-19 (the $7^{\text {th }}$ version so far).

* Correspondence: mapenglin1@163.com

'Department of Intensive Care, Peking University Third Hospital, 49 North Garden Road, Haidian District, Beijing 100191, P. R. China

Full list of author information is available at the end of the article

C C The Author(s). 2020 Open Access This article is licensed under a Creative Commons Attribution 4.0 International License, which permits use, sharing, adaptation, distribution and reproduction in any medium or format, as long as you give appropriate credit to the original author(s) and the source, provide a link to the Creative Commons licence, and indicate if changes were made. The images or other third party material in this article are included in the article's Creative Commons licence, unless indicated otherwise in a credit line to the material. If material is not included in the article's Creative Commons licence and your intended use is not permitted by statutory regulation or exceeds the permitted use, you will need to obtain permission directly from the copyright holder. To view a copy of this licence, visit http://creativecommons.org/licenses/by/4.0/. The Creative Commons Public Domain Dedication waiver (http://creativecommons.org/publicdomain/zero/1.0/) applies to the data made available in this article, unless otherwise stated in a credit line to the data. 


\section{(Continued from previous page)}

Main outcomes: The primary endpoint is a composite of newly developed or exacerbated organ dysfunction. This is defined as an increase in the sequential organ failure assessment (SOFA) score of two or more, indicating sepsis and involvement of at least one organ. The SOFA score will be measured for the 14 days after enrolment from the baseline (the score at randomization).

The secondary endpoints are shown below:

- sOFA score in total

- Pneumonia severity index score

- Dosage of vasoactive drugs

- Ventilation free days within 28 days

- Length of stay in intensive care unit

- Total hospital costs to treat the patient

- 28-day mortality

- The incidence of adverse drug events related to SFI

Randomisation: The block randomization codes were generated by SAS V.9.1 for allocation of participants in this study. The ratio of random distribution is 1:1. The sealed envelope method is used for allocation concealment.

Blinding (masking): The patients and statistical personnel analyzing study data are both blinded. The blinding of group assignment is not adopted for the medical staff.

Numbers to be randomised (sample size): This study is expected to recruit 300 patients with COVID-19, (150 in each group).

Trial Status: Protocol version 2.0, February 15, 2020.

Patient recruitment started on February 25, and will end on August 31, 2020.

Trial registration: Chinese Clinical Trial Registry: ChiCTR2000030043. Registered February 21, 2020, http://www.chictr.org. cn/showprojen.aspx?proj=49866

Full protocol: The full protocol is attached as an additional file, accessible from the Trials website (Additional file 1). In the interest in expediting dissemination of this material, the familiar formatting has been eliminated; this letter serves as a summary of the key elements of the full protocol.

Keywords: COVID-19, Shenfu injection, randomised controlled trial, protocol

\section{Supplementary information}

Supplementary information accompanies this paper at https://doi.org/10. 1186/s13063-020-04677-5.

Additional file 1. Full Study Protocol.

\section{Acknowledgements}

We thank Lin Zeng for her advice on statistics. And we appreciate Xin Wang, Hai-Qin Liu and Jing Luo for their sincere support in study design, ethical issues, research registry, and implementation.

\section{Authors' contributions}

PLM conceived and designed the study. ZYW wrote the study protocol and provided critical revisions that are important for the intellectual content. SZF, LX, SSL, KJQ, XDH, GCZ, LHL, JZ, WFL, BYQ and CLZ are responsible for recruiting patients and collecting data. All authors approved the final version of the manuscript.

\section{Funding}

This study has received support from Bethune Charitable Foundation (identifier B-0301-H-20200304), which is not involved in the design of the study and collection, analysis, and interpretation of data and in writing the manuscript.

\section{Availability of data and materials}

P.L.M and Z.Y.W will have access to the final trial dataset. The dataset will be available after being authorized by the corresponding author on reasonable request. The contact e-mail address is mapenglin1@163.com.
Ethics approval and consent to participate

Peking University Third Hospital Medical Science Research Ethics Committee reviewed and approved the study protocol on February 19, 2020 (serial number IRB00006761-M2020045). This trial has received ethical approval from the appropriate ethical committee as described above. Informed consent will be obtained from all the eligible patients or their next of kin.

\section{Consent for publication}

Not applicable

\section{Competing interests}

The authors declare that they have no competing interests.

\section{Author details}

'Department of Intensive Care, Peking University Third Hospital, 49 North Garden Road, Haidian District, Beijing 100191, P. R. China. ²Department of Intensive Care Unit/Emergency, Wuhan Third Hospital, Wuhan university, Wuhan, Hubei, P. R. China. ${ }^{3}$ Department of Critical Care Medicine, Wuchang Hospital, Wuhan, Hubei, P. R. China. ${ }^{4}$ Department of Emergency and Critical Care Medicine, Tongji Hospital, Tongji Medical College, Huazhong University of Science and Technology, Wuhan, Hubei, P. R. China. ${ }^{5}$ Department of Critical Care Medicine, The First Affiliated Hospital of Nanchang University, Nanchang, Jiangxi, P. R. China. ${ }^{6}$ Department of Intensive Care Unit, The First Affiliated Hospital of Bengbu Medical College, Bengbu, Anhui, P. R. China. ${ }^{7}$ Department of Critical Care Medicine, The Affiliated Hospital of Jianghan University, Wuhan, Hubei, P. R. China. ${ }^{8}$ Department of Intensive Care Unit, Jingzhou Central Hospital, The Second Clinical Medical College, Yangtze University, Jingzhou, Hubei, P. R. China. ${ }^{9}$ Department of Critical Care Medicine, Wuhan Hospital of Traditional Chinese Medicine, Wuhan, Hubei, P. 
R. China. ${ }^{10}$ Department of Emergency and Critical Care, Changzheng Hospital, Naval Medical University, Shanghai, P. R. China. "Department of Critical Care Medicine, Henan Provincial People's Hospital, Zhengzhou, Henan, P. R. China. ${ }^{12}$ Intensive Care Medicine, Eastern Campus, Renmin Hospital of Wuhan University, Wuhan, Hubei, P. R. China.

Received: 7 August 2020 Accepted: 12 August 2020

Published online: 24 August 2020

\section{Publisher's Note}

Springer Nature remains neutral with regard to jurisdictional claims in published maps and institutional affiliations.

Ready to submit your research? Choose BMC and benefit from:

- fast, convenient online submission

- thorough peer review by experienced researchers in your field

- rapid publication on acceptance

- support for research data, including large and complex data types

- gold Open Access which fosters wider collaboration and increased citations

- maximum visibility for your research: over $100 \mathrm{M}$ website views per year

At BMC, research is always in progress.

Learn more biomedcentral.com/submissions 